\title{
The Making of Contemporary Australian Monetary Policy - Backward- or Forward- Looking?
}

\author{
Ying Chen ${ }^{1}$, Hanyang Zhang ${ }^{1}$, Kwok-Leung Tam $^{2} \&$ Maoguo $\mathrm{Wu}^{1}$ \\ ${ }^{1}$ SHU-UTS SILC Business School, Shanghai University, Shanghai, China \\ ${ }^{2}$ Insearch, University of Technology Sydney, Australia \\ Correspondence: Hanyang Zhang, SHU-UTS SILC Business School, Shanghai University, 20 Chengzhong Road, \\ Jiading District, Shanghai 201899, People's Republic of China.
}

Received: April 10, 2018

Accepted: April 21, 2018

Online Published: May 10, 2018

doi:10.5539/ijef.v10n6p127

URL: https://doi.org/10.5539/ijef.v10n6p127

\begin{abstract}
Monetary authorities rarely disclose the true reasons behind their policy reactions. A tracing of the policy reaction function to see if the monetary authority is applying simple rules holds the potential to offer profound insight into the past behavioral relationship between the monetary authority and economic agencies. A reasonable body of knowledge about the direction of monetary policy would, moreover, assist economic agencies in forming their expectations, which would in turn, be useful for the monetary authority in anticipating the likely trends of the overall economy. The main objective of this study is to track de Brouwer and Gilbert (2005) from the Australian financial deregulation era (from 1983 to 2002) to the present. Empirical findings show that the Reserve Bank of Australia (RBA) is more forward-looking when formulating monetary policy rather than backward-looking, and that inflation targeting plays a significant role in stabilizing the output of the economy.
\end{abstract}

Keywords: backward-looking, forward-looking, generalized method of moments

\section{Introduction}

According to the RBA charter, monetary policy represents the central instrument for maintaining low, stable inflation, stabilizing the home currency, preserving the full employment level, maintaining economic prosperity and the welfare of the citizen and maximizing the sustainability of economic growth. Most major central banks use the interest rate on overnight loans in the money market ('the cash rate') as a tool of monetary policy (Note 1). An important question is how to set the cash rate for achieving the objectives of monetary policy. A large number of methods have been used to set the cash rate, with the most popular methodology being known as the Taylor rule. From a historical perspective, the Taylor rule has been widely used as a benchmark for measuring monetary policy achievement.

Quite a few simple interest rate feedback rules have been proposed for assessment of the cash rate. Among those are the nominal income level rule, the nominal income growth rule, the price level rule, the Taylor rule, the inflation only rule, the change rule, and the constant real interest rate rule. de Brouwer and O'Regan (1997) examine the abovementioned rules and claim that ultimately none of the efficient frontiers for any of the rules reduces the variability in inflation or output to zero. Nevertheless, the policy that unambiguously makes the best effort is found in the Taylor rule. The Taylor rule clearly leads to a lower variability of inflation and output. It also argues that inflation is caused by recent excess demand domestically. Reacting to the strength of demand indicated by the output gap, would thus lower the inflation variability accordingly. Orphanides (2007) reviews the theoretical studies of monetary rules and argues that the simplest monetary policy rule is found in Milton Friedman's k-percent rule. Friedman (1960) advises that the constant growth rate of the money supply should be similar to the growth rate of potential output. He also recommends constant growth of the money supply. This rule only requires a small amount of information to implement the policy, which implies that Friedman's rule ignores the importance of the interest rate instrument. In contrast, Taylor (1993) argues that creating and maintaining target inflation would stabilize not only the financial market but also macroeconomic performance. He advocates for the direct linkage between the interest rate, inflation, and economic activities. Hence, the Taylor rule provides a convenient framework for analyzing monetary policy that neglects the effects of money demand and money supply. 
This study investigates the RBA's reaction functions in setting the cash rate in the post-exchange rate float period after 1984, and in particular, focuses on the period after 1993 when the RBA introduced inflation targeting. The full sample period commences from quarter 1, 1984, to quarter 4, 2014. The subsample, or inflation targeting period, starts from quarter 1, 1993 to quarter 4, 2014. The inflation targeting approach allows monetary policy to intervene and stabilize fluctuations in output over the business cycle. Achieving the target rate would instill discipline in monetary policymakers, and would serve as an anchor for private-sector expectations for inflation. Furthermore, this study mainly attempts to investigate whether the RBA's monetary policy emphasizes a specific rule. While a great deal of previous research gauges the efficiency and behavior of major central banks in devising their monetary policies, a lack of systematic empirical analysis is evident on how the RBA sets its monetary policy to sustain the Australian economy. The latest empirical study is by de Brouwer and Gilbert (2005), which uses data until 2002.

A series of important assumptions are made for this study. First, Orphanides (1998) recommends that policymakers use real-time data. This study uses final release data since these data are more likely to represent specific economic activities. There are two unobservable variables in the Taylor rule, which are, namely, target inflation and potential output. The Hodrick-Prescott (HP) filter is utilized to generate the potential GDP and thus the output gap. The HP filter is used extensively in empirical macro-economic research to isolate the cyclical element of a time series from raw data. This study assumes $2.5 \%$ of inflation target which is the average of the target band (2-3\%). Third, this study distinguishes between backward-looking and forward-looking reaction functions. The backward-looking function uses historical data to determine the cash rate, while the forward-looking function specifies the forecast profile for both inflation and the output gap one year in advance. This study estimates and compares both rules. To estimate the parameters in the forward-looking rule, this study uses the generalized method of moments (GMM). A key in GMM is a set of the population moment conditions that are derived from the assumptions about the econometric model.

Overall, this study investigates the following questions. Does the RBA construct variables other than inflation and output gap? What are the implications of inflation targeting on monetary policy? What is the natural interest rate implied by the model? Comparing the backward-looking and forward-looking functions, which one is more efficient and which one gives a better outlook on the monetary policy reaction function? Moreover, is the Australian monetary policy sensitive to other developed economies' monetary policies or other main trading partners' monetary policies?

The remaining part of this study is organized as follows. Section 2 reviews related literature. Section 3 introduces the simple reaction function of the Taylor rule followed by a description of the data and variables that are used in the Ordinary Least Square (OLS) and the GMM model in Section 4. Section 5 is based on the equation in Section 3. OLS is utilized to estimate parameters in the backward-looking reaction function. Section 6 derives the equation for the forward-looking reaction function and uses the GMM routine for obtaining empirical results. Section 7 composes the out-of-sample forecasts for both backward-looking and forward-looking specifications. The main findings of this study, directions of future study, and the answers to the questions raised above, are all provided in Section 8.

\section{Related Literature}

Taylor (1993) states that policy rules that concentrate on exchange rates or the money supply do not convey as good an output or price variability as policies that target price level and real output directly. In his work, he advocates for monetary policies where the short-term cash rate is increased or decreased when the price level and real income level deviate from their targets. The uncertainty is in how much the cash rate should change to meet the central bank's purposes. While Taylor (1993) investigates U.S. economic performance, this empirical study focuses on Australian economic conditions.

On the basis of Taylor (1993), Clarida et al. (1998) derives a forward-looking version of the simple backward-looking reaction function. It estimates the reaction function with expectation variables and argues that targeting inflation is effective and a major component of output stabilization. By targeting inflation, monetary authorities would be able to increase the nominal interest rate effectively to raise the real interest rate if expected inflation exceeded its target in the long run.

Taylor (1993) indicates that under the floated exchange rate system, the central bank can easily adjust the short-term cash rate in relation to deviations in price level and real output from their potential level. Yet in fixed exchange rate regimes, countries cannot adjust their interest rate independently since they have to consider the shift in other countries' monetary policies in order to maintain its pegged exchange rate. Output and inflation perform better under a floated exchange rate scheme compared with a fixed exchange rate scheme. Clarida $e t$ al. 
(1998) states that building credibility through a fixed exchange rate regime is tough due to the failure of monetary control, which puts pressure on the economy. Edey (2006) finds that the Taylor rule gives an accurate explanation of the federal funds rate in the United States since 1987. The most recent empirical paper about Australian monetary policy reaction function is by de Brouwer and Gilbert (2005), which examines the backward-looking and forward-looking Taylor rule using Australian data up to 2002.

For his part, Orphanides $(1998,2000)$ argues that policymakers use real-time data that are available at the moment that they make their decision, while studies by such scholars as Taylor (1999) and Clarida et al. (1998), prefer to utilize final release data. Orphanides (2004) indicates that estimated output gaps are effective for explaining subsequent fluctuations in inflation. Gruen et al. (2005) and Orphanides (2001) implement the Phillips Curve to generate the output gap, which dominates the HP filter. de Brouwer and Gilbert (2005) indicate that the standard errors from regression and implied cash rates are not distinguished under these different data sets and technical approaches. They all explain central bank decisions similarly. Hence, there is no optimal data set or technique.

Meanwhile, Lee et al. (2011) establishes a novel methodology for the Taylor rule. He advocates that instead of using one rule to formulate the cash rate, central banks should judge between several rules, weight them and take the average interest rate to adjust monetary policy accordingly. A reasonable weighting would be when higher weights are given to the rules which demonstrate better past performance than others. As with the Taylor rule, it applies to several methods using different measurements of inflation and different techniques for deriving the output gap, weights them and then applies the fitted cash rate to evaluate central banks' policies. Lee et al. (2011) calls the resulting rule the "meta Taylor rule" and employs it to investigate U.S. monetary policy. Lee et al. (2012) does the same with the U.K. and Australian monetary policies. The results demonstrate that the novel approach is useful and applicable in terms of both behavioral modelling and inference perspective, offering an overall highly flexible instrument with which to model and describe policymakers' decisions. The novel model cannot only adjust the uncertainties of parameter estimates and unexpected shocks, but also it can further adjust the uncertainties attached to the measures of variables used in decision-making. The results indicate that the "meta Taylor rule" offers a flexible and reliable prescription of monetary policy in those countries.

However, according to Bernanke (2010), the limitation of the Taylor rule is that in a given episode, such as when the U.S. short-term nominal interest rate hits the zero lower bounds (ZLB), the cash rate cannot be reduced further. Therefore, using the Taylor rule as a framework of monetary policy does not present itself as a reasonable option. At the ZLB, monetary policy cannot be set with a nominal interest rate (Orphanides, 2007). Since Australia has not experienced such a case as with the U.S. economy, applying the Taylor rule to examine the RBA's decisions stands to be reasonable and effective.

\section{Simple Reaction Function}

The Taylor rule is regularly known as a simple monetary policy rule that describes how central banks change the short-term nominal cash rate in response to inflation movements and macroeconomic fluctuations. It presents a simple and transparent framework for the study of historical monetary policy and for the econometric assessment of alternative strategies that central banks can use as an anchor for their interest rate policy. The rule is also adopted as a tool for review of monetary policy. It has simplified the analysis of monetary policy both in practice and in empirical research. The primary formulation of the simple policy reaction function applied in literature on monetary policy is as follows.

$$
i_{t}=\bar{\imath}+\beta\left(\pi-\pi^{*}\right)+\gamma\left(y-y^{*}\right)
$$

where $i$ is the short-term nominal cash rate, $\bar{l}$ is the neutral rate of interest, $\pi$ is the inflation rate, and $y$ is the real output. The subscript $\mathrm{t}$ denotes the time period of investigation, and the asterisk denotes the target or potential value of variables. $\beta$ and $\gamma$ constitute parameters representing the weight of inflation and output, respectively.

The equation states that policymakers make changes in the interest rate in response to deviations from the target or the potential value of variables. Taylor (1993) argues that $\beta$ being greater than 1 means that the nominal cash rate should be adjusted for the purpose of stabilizing inflation. $\beta$ being greater than 1 is commonly known as the "Taylor principle". If it is less than 1 , the nominal cash rate adjusts to accommodate for the divergence in inflation. If the estimated value of $\beta$ is significantly higher than $\gamma$, the central banks consider inflation variability to be more important than the output gap variability and vice versa. Following Taylor (1999), previous periods of inflation and output should be used as the primary information set for guiding the instrument path. The backward-looking reaction function is computed on the basis of historical data, while the forward-looking reaction function is computed on the basis of a one year forecast profile of the inflation gap and the output gap. 


\section{The Data}

The data are gathered from the Australian Bureau of Statistic (ABS). The inflation rate is measured by the change in CPI. The target inflation rate is assumed to be $2.5 \%$, i.e., average of the target range $(2 \%-3 \%)$. While Taylor (1993) originally uses the GDP deflator as an inflation measurement, CPI is the preferred measurement of the inflation rate. The GDP deflator contains only goods and services manufactured domestically, while the CPI further covers imported goods and services. This implies that the CPI can more accurately specify changes in the price level in response to average consumption. This is especially appropriate for Australia, as Australia imports more than it exports and the major export base constitutes raw materials which are not consumable goods. Changes in the prices of imported goods and services would heavily influence the inflation rate in Australia. Furthermore, the GDP deflator includes prices of capital goods, while the CPI excludes them, implying that the GDP deflator is less likely to capture the inflation rate specifically compared to the CPI (Note 2). The GDP employs real GDP, not nominal GDP, since nominal GDP does not eliminate the GDP deflator or the inflation index. The figure below shows the results from using the HP filter to determine the potential GDP and the output gap.

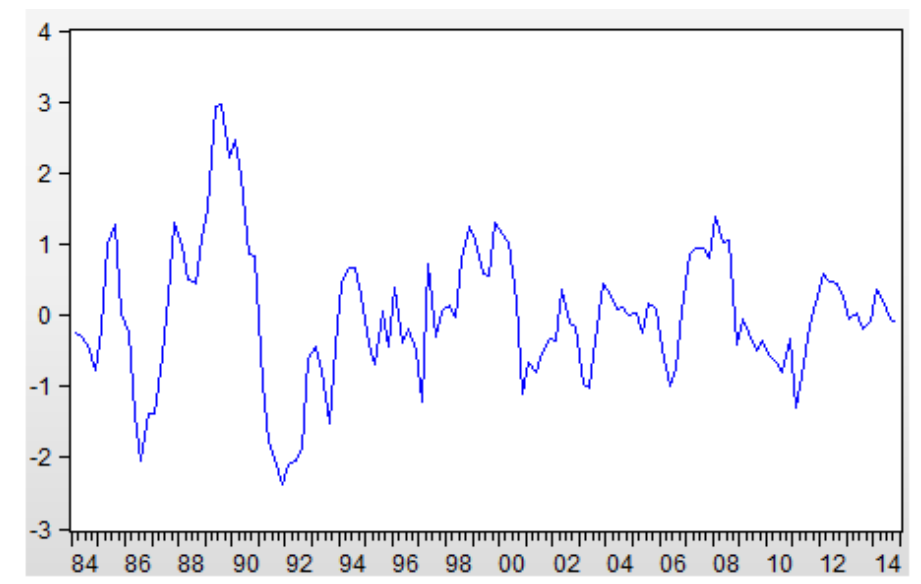

Figure 1. Output gap

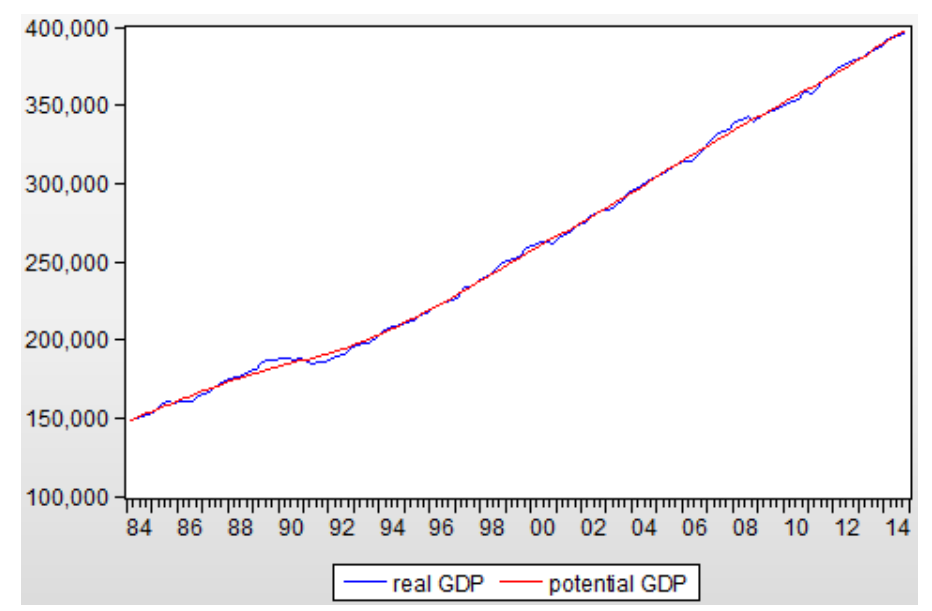

Figure 2. Real GDP versus potential GDP derived from the HP filter

A striking feature of Figure 1 and Figure 2 is the recession in the early 1990s when the Australian economy was affected by the savings and loan crisis in North America. The crisis began when Japan and Germany increased their interest rates heavily, pressuring U.S. cash rates also to rise, leading to a massive sell-off of shares in the U.S. market. Share prices declined by $25 \%$ on average globally, but Australia saw a $40 \%$ collapse in its share market. Most of the major OECD economies experienced an economic downturn in the early 1990s. Real output fell below the potential level. Apart from that, in 2008, it can be seen that real output exceeded the potential level. Meanwhile, the global financial crisis (GFC) led to recession in many developed countries. Australia's economy was spared from the recession due to the economic boom in China, resulting in large demand for raw materials from Australia. 
Apart from just the inflation and output gap, the forward-looking function also considers the unemployment rate, the exchange rate, and the world interest rate. The federal funds rate is utilized to measure the world interest rate, as the U.S. monetary policy significantly influences the world economy and also the economic information set of the RBA. This does not mean that the RBA's decisions are heavily dependent on U.S. monetary policy but that the RBA considers changes in the U.S. interest rate as an important element for determining its actions. Hence, the exchange rate also specifies the value of the Australian dollar in terms of the U.S. dollar. Figure 3 shows the federal funds rate, where it can be seen that the rate has been below the ZLB since 2008. The Federal Reserve had to cut interest rates several times in order to help the U.S. economy recover. In this case, the Taylor rule is not applicable. Figure 4 shows that in the period between 2009 and 2010, the Australian dollar depreciated deeply but then appreciated until it hit a peak in 2012 .

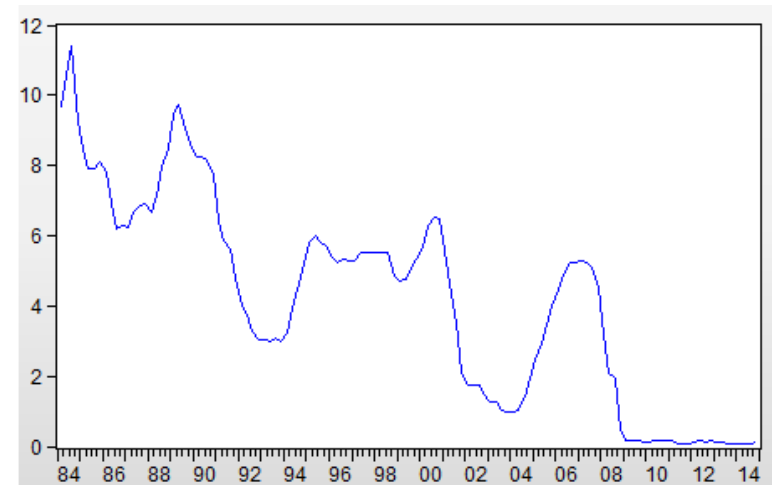

Figure 3. Federal funds rates

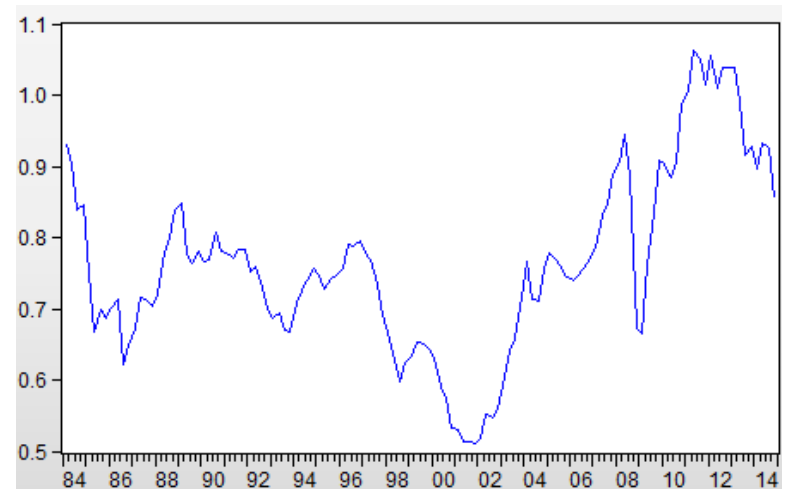

Figure 4. USD/AUD exchange rates

The unemployment rate is positively related to the output level, representing an outlook of the entire economy. Including the unemployment rate would thus produce better performance on the part of the reaction function. Figure 5 shows the Australian unemployment rate. The increase in the unemployment rate in 2009 is in line with the effects of the GFC. The unemployment rate surging from 2012 onwards explains the recent cash rate cut.

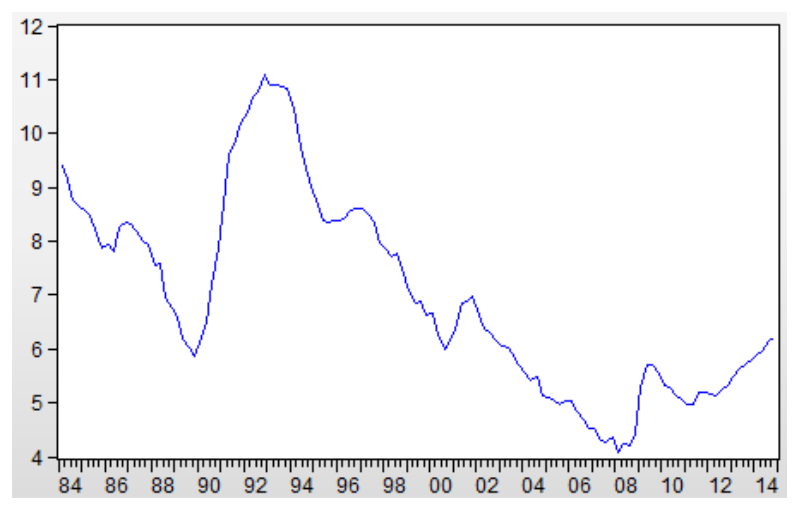

Figure 5. Australian unemployment rate 
Figure 6 illustrates deviations in inflation from the inflation target. Since 1993, when the RBA adopted target inflation, Australia has experienced a period of stable inflation, as it contributed to the maintenance of inflation within its target band as well as to the stabilizing of economic activity.

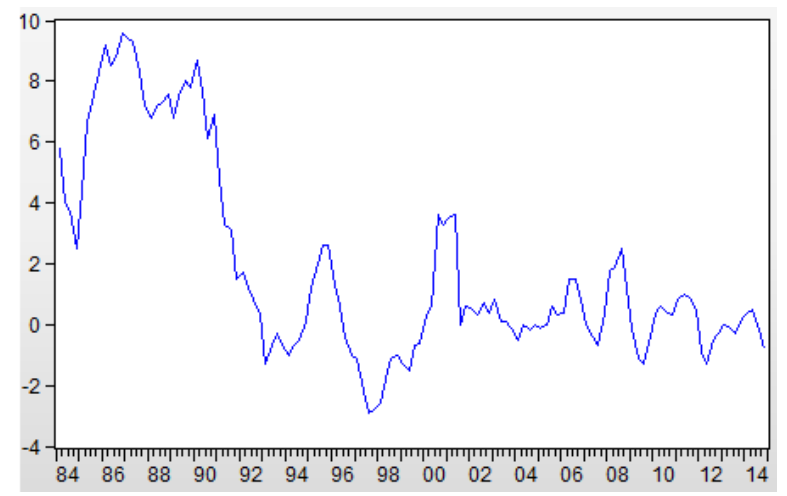

Figure 6. Deviations from the inflation target

Figure 7 represents the actual cash rate generated by the RBA. During the inflation targeting period, interest rates moved in a quite flat direction as a result of inflation and output stabilization.

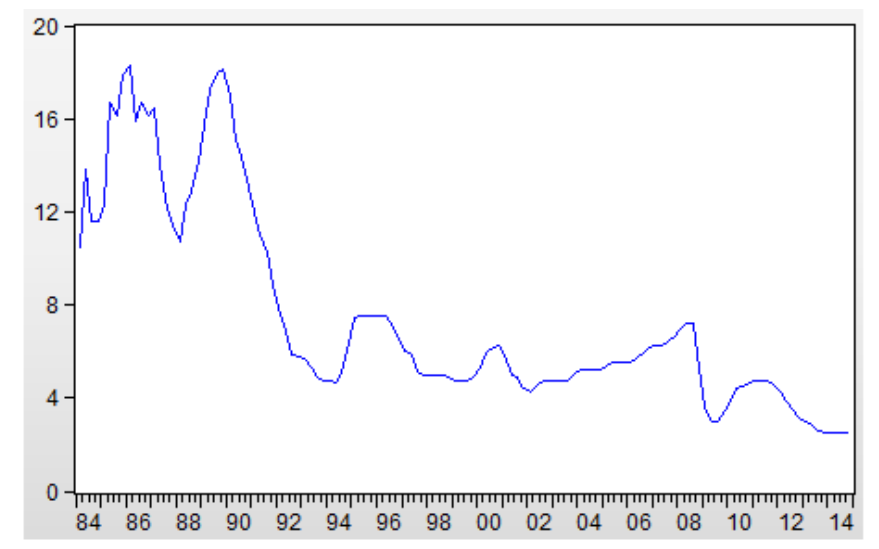

Figure 7. The RBA actual cash rate

\section{Backward-Looking Reaction Function}

The Taylor rule is generally recognized as a backward-looking reaction function since people assume that the monetary authority's decisions rely on current and previous inflation diversion and on the output gap. This study uses the value of the inflation deviation and output gap lagged one period. The Taylor rule with backward-looking function is estimated using the Ordinary Lease Square (OLS) estimation.

Table 1. Estimated backward-looking reaction functions (Post floated exchange rate period 1984Q2 - 2014Q4)

\begin{tabular}{ccccc}
\hline Constant & Inflation Gap (t-1) & Output Gap (t-1) & Standard Error & Adjusted $R^{2}$ \\
\hline 5.23 & 1.17 & 0.5 & \multirow{2}{*}{1.89} & 0.81 \\
$(0.00)$ & $(0.00)$ & $(0.00)$ & & \\
\hline
\end{tabular}

Table 1 shows the estimated coefficients of the inflation deviation and the output gap using the backward-looking reaction function. The model uses one quarter of the lagged values from the inflation gap and the output gap. The outcomes from the full sample period show that both the inflation parameter $\beta$ and the output parameter $\gamma$ are significant. $\beta$ is greater than 1 , which indicates that the Australian monetary authority adjusts the target nominal interest rate to stabilize inflation within the target range. Yet, it is lower than the estimated value from de Brouwer and Gilbert (2005) due to the fact that only data up to 2002 are investigated, while this study includes more recent periods. Figure 3 shows that after 2002, deviations in inflation became less volatile, meaning that inflation is captured well, which might be a reason for policymakers to reduce the weight 
on inflation (Note 3). The output gap parameter is significant, but less than 1, which means that the RBA still treats inflation variability as more important than output gap variability. Compared with previous findings, the weight on the output gap is significantly lower, but the weight is positive. Hence, policymakers still consider the role of the output gap when making decisions.

Table 2. Estimated backward-looking reaction functions (Inflation targeting period 1993Q2 - 2014Q4)

\begin{tabular}{ccccc}
\hline Constant & Inflation Gap (t-1) & Output Gap (t-1) & Standard Error & Adjusted $R^{2}$ \\
\hline 5.0 & 0.36 & 0.40 & \multirow{2}{*}{0.23} & 0.12 \\
$(0.00)$ & $(0.00)$ & $(0.06)$ & & \\
\hline
\end{tabular}

Table 2 shows the regression results of the subsample period, in which the output gap parameters and the inflation gap parameters are still statistically significant but the coefficient of the inflation gap is smaller than the coefficient of output gap. $\beta$ is less than 1 , and the standard error is larger than that of previous studies, partly because the sampling period is different and the sampling period covers a longer period of time, including the period of the GFC. During this period, frequent fluctuation in the cash rate series took place. Figure 7 shows the actual movement of the short-term nominal cash rate. A striking feature is that after 1993 when the RBA adopted inflation targeting, the interest rate movement became much flatter than it had been in past. This explains why the adjusted $R^{2}$ is much smaller in the sub-sample period and also the much lower values of inflation variability and output variability.

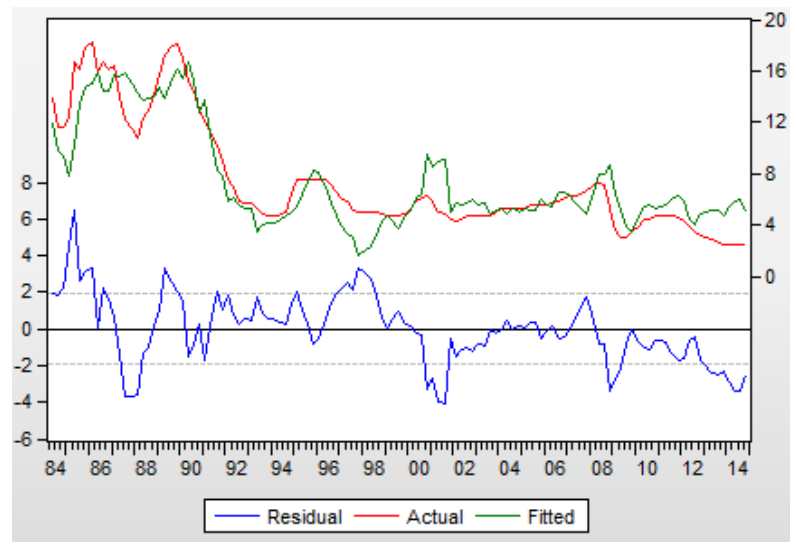

Figure 8. Predicted cash rate versus actual cash rate

Figure 8 indicates that under the backward-looking reaction function, the fitted cash rate is in line with the actual cash rate. The prediction significantly overstates RBA's actions in the early 2000s and 2008 with an unpredicted financial crisis that forced the RBA to cut the interest rate deeply. In addition, the implied cash rate greatly understates the actual cash rate in the beginning of the post-floated cash rate period, i.e., late 1980s and second half of the 1990s.

The simple backward-looking reaction function serves as a benchmark for investigating monetary policy. On the other hand, on account of the simplicity of the rule in which it considers only the inflation gap and the output gap, it forgoes many other crucial economic variables such as the unemployment rate, the exchange rate and the world interest rate.

\section{Forward-Looking Reaction Function}

The simple backward-looking reaction function described above depends on lagged values of deviations in inflation from the target inflation and the output gap. However, it neglects one important aspect - the perspective of forward-looking monetary policy formulation. In practice, monetary policymakers often tend to base their monetary policy decision-making on a rational outlook - expectation of future values of policy variables, available information, and past experiences. Previous research, including by Clarida et al. (1998), Batini (1999), de Brouwer and Gilbert (2005), and so forth, argues that the forward-looking reaction function specification outperforms the backward-looking one in evaluating monetary policy behavior.

Clarida et al. (2000) casts the Bryant-Hooper-Mann rule (1993) in a forward-looking framework and proposes a simple baseline forward-looking specification of the reaction function in which the target interest rate $\left(i_{t}^{*}\right)$ relies 
on a neutral nominal interest rate $(\bar{l})$, the expected deviation of inflation from the target inflation $\left[E\left(\pi_{t+n} \mid \Omega_{t}\right)-\right.$ $\left.\pi^{*}\right]$ as well as the expected output gap $\left[E\left(y_{t} \mid \Omega_{t}\right)-y^{*}\right]$,

$$
i_{t}^{*}=\bar{\imath}+\beta\left[E\left(\pi_{t+n} \mid \Omega_{t}\right)-\pi^{*}\right]+\gamma\left[E\left(y_{t+m} \mid \Omega_{t}\right)-y^{*}\right]
$$

where $\Omega_{t}$ is the information set available to the monetary authority at time $\mathrm{t}$ when it sets the interest rate.

Since the monetary authority often tends to avoid a loss in credibility from large impulsive changes in policy instrumental variables, it is assumed that it smooths out interest rates by adjusting them partially to the target,

$$
i_{t}=(1-\rho) i_{t}^{*}+\rho i_{t-1}+v_{t}
$$

where $\rho$ is a smoothing factor, $0<\rho<1$. Larger values of $\rho$ actually reduce the level of smoothing, and in the limiting case with $\rho=1$, the cash rate series is just the same as the original series with a lag time of one unit. Hence, values of $\rho$ close to 1 have less of a smoothing effect and give greater weight to recent changes in the data, while values of $\rho$ closer to 0 have a greater smoothing effect and respond less to recent changes.

Letting $\alpha \equiv \bar{\imath}-\beta \pi^{*}$ and $x_{t} \equiv y_{t}-y_{t}^{*}$ and then substituting equation (3) into equation (2) yields

$$
i_{t}=(1-\rho)\left[\alpha+\beta E\left(\pi_{t+n} \mid \Omega_{t}\right)+\gamma E\left(x_{t+m} \mid \Omega_{t}\right)\right]+\rho i_{t-1}+v_{t}
$$

where $v_{t} \in \Omega_{t}$ which is orthogonal to $\varepsilon_{t}$. Assuming rational expectations, the equation (4) can be written in terms of realized variables as

$$
i_{t}=(1-\rho) \alpha+(1-\rho) \beta \pi_{t+n}+(1-\rho) \gamma x_{t+m}+\rho i_{t-1}+\varepsilon_{t}
$$

where $\varepsilon_{t}=v_{t}-(1-\rho) \beta\left[\pi_{t+n}-E\left(\pi_{t+n} \mid \Omega_{t}\right)\right]-(1-\rho) \gamma\left[x_{t+m}-E\left(x_{t+m} \mid \Omega_{t}\right)\right]$.

Let $u_{t}$ be the monetary authority's instrument set at the time it chooses the interest rate. This information set is orthogonal to the error term in the base line equation (5), i.e., $\mathrm{E}\left(\varepsilon_{t} \mid u_{t}\right)=0$. Equation (5) implies the following orthogonality condition,

$$
\mathrm{E}\left\{i_{t}-(1-\rho) \alpha-(1-\rho) \beta \pi_{t+n}-(1-\rho) \gamma x_{t+m}-\rho i_{t-1} \mid u_{t}\right\}=0 .
$$

The estimation issue arising from equation (5) is that the conventional ordinary least square (OLS) estimation gives inconsistent estimates because $\pi_{t+n}$ is correlated with $\varepsilon_{t}$. To circumvent this issue, Clarida et al. (1998) suggests estimating the unknown parameters $(\alpha, \rho, \beta, \gamma)$ in equation (5) via the GMM method with a vector of instrumental variables that are part of the information set $\mathrm{t}$ and are orthogonal to $\varepsilon_{t}$. In other words, this vector of instrumental variables comprises the monetary authority's information set at the time it determines the interest rate. On top of that, it should not be correlated with $v_{t}$.

Given equation (2), an equilibrium relation of the real interest rate can be written as follows:

$$
r_{t}^{*}=\bar{r}+(\beta-1)\left[E\left(\pi_{t+n} \mid \Omega_{t}\right)-\pi^{*}\right]+\gamma\left[E\left(y_{t+m} \mid \Omega_{t}\right)-y^{*}\right],
$$

where $\bar{r}$ is the equilibrium interest rate independent of monetary policy. Equation (7) illustrates the critical role of parameter $\beta$. If $\beta>1$, the target real interest rate is adjusted to stabilize inflation. If $0<\beta<1$, it moves to accommodate inflation, i.e., the monetary authority raises the nominal interest rate in response to an expected rise in inflation, but it does not increase it sufficiently to keep the real interest rate from declining. Clarida et al. (2000) shows that $0<\beta<1$ is consistent with the possibility of persistent, self-fulfilling fluctuation in inflation and output. Hence, $\beta=1$ is a crucial discriminatory criterion for judging the central bank's behavior.

Finally, it is possible to use the fitted values for the parameters $\alpha$ and $\beta$ to recover an estimate of the monetary authority's constant target inflation rate $\pi^{*}$. Although the empirical model does not identify the equilibrium inflation rate and the equilibrium real interest rate separately, it does provide a relationship between them, conditional upon $\alpha$ and $\beta$. Given that $\alpha \equiv \bar{\imath}-\beta \pi^{*}$ and $\bar{r}=\bar{\imath}-\pi^{*}$, the target inflation rate is

$$
\pi^{*}=\frac{\bar{r}-\alpha}{\beta-1} \text {. }
$$

It establishes a relationship between the target inflation rate and the equilibrium real interest rate defined by the parameters $\alpha$ and $\beta$ in the policy rule. Clarida et al. (1998) sets the real interest rate to the average in the sample and uses the equation (8) to recover the implied value of $\pi^{*}$.

\section{Forward-Looking Reaction Function - Empirical Results}

Following de Brouwer and Gilbert (2005), the forward-looking reaction functions are run for the full sample period (1984Q1 - 2014Q4) as well as for the subsample period (1993Q1 - 2014Q4). In order to obtain GMM estimates, the moment conditions must be written as an orthogonality condition between an expression including the parameters and a set of instrumental variables. Moreover, there has to be at least as many instruments as there are parameters, in order for estimates of the GMM estimator to be identified. For the full sample period 
(1984Q1-2014Q4), the instrumental variables chosen are the constant, the second lag of the cash rate, the first lag of inflation, the first lag of the output gap, the second lag of the AUD to USD exchange rate, the first four lags of the federal funds rate, and the first four lags of the Australian unemployment rate. This base set of instruments is in line with de Brouwer and Gilbert (2005) except that the unemployment rate is included as a valid instrument since there is always a link between unemployment and inflation. Inflation is forecast 4 quarters ahead of time, while the output is forecast at 1 quarter in advance. The following table reports estimation results.

Table 3. Estimated forward-looking reaction functions (Post Floated Era 1984Q1 - 2014Q4)

\begin{tabular}{ccccccc}
\hline Constant & Cash Rate $(\mathrm{t}-1)$ & Inflation $(\mathrm{t}+\mathrm{n})$ & Output Gap $(\mathrm{t}+\mathrm{m})$ & Standard Error & Adjusted $R^{2}$ & J-Test \\
\hline \multirow{2}{*}{6.21} & 0.88 & 1.36 & 2.32 & & & 0.79 \\
$(0.00)$ & $(0.00)$ & $(0.00)$ & $(0.00)$ & $(0.90)$ & 0.96 & $(4)$ \\
\hline
\end{tabular}

Note. The instrument list includes cash rate (-2), inflation rate (-1), output gap (-1), exchange rate (-2), federal funds rate (-1 to -4$)$ and the unemployment rate $(-1$ to -4$)$. The numbers in the brackets next to the standard error are the standard errors from the backward-looking response function when it adds the cash rate lagged by one period in the regression model. The significant level of parameters is 5 per cent. The J-test statistic shows the over-identification, indicating whether the model's moment conditions match the data well or not. The numbers in the brackets next to the test statistic are the degree of freedom which equals the number of instruments subtracted from the number of parameters estimated.

The four parameter estimates are $\hat{\alpha}=6.21, \hat{\rho}=0.88, \hat{\beta}=1.36$, and $\hat{\gamma}=2.32$. Apart from the longer sampling period, the estimates, as a whole, are in line with those obtained by de Brouwer and Gilbert (2005). The magnitude of the parameter $\beta$ is critical here. Since $\hat{\beta}>1$, the target real interest rate is adjusted to stabilize inflation and output (for $\hat{\gamma}>0$ ). In addition, if inflation goes up by $1 \%$, the monetary authority is predicted to raise interest rates by $1.36 \%$. In order to examine the validity of the model (i.e., the validity of instruments), a J-test is conducted and asymptotically Chi-squared with 4 degrees of freedom ( 8 instruments minus 4 parameters). The J-test statistic is 0.788687 with the corresponding p-value of 0.852171 . Since the $\mathrm{p}$-value is very large, the validity of the instrument and overall specification of the model cannot be rejected.

In addition, the standard error of the estimate is 0.89 and therefore smaller than that of de Brouwer and Gilbert (2005), implying a better overall fit of the estimated model of the cash rate data. The results indicate that the output gap tends to dominate inflation in the reaction function of the post-floated period. Recall that excess demand is a main driver of inflation. Thus, when output is above its potential level, inflation tends to increase.

Another GMM estimation is performed over the subsample period (1993Q1 - 2014Q4). This subsample period marks the era when the RBA first set this inflation target rate in 1993. Table 4 presents the estimation results of the subsample period.

Table 4. Estimated forward-looking reaction functions (Inflation Targeting Period 1993Q4 - 2013Q4)

\begin{tabular}{ccccccc}
\hline Constant & Cash Rate $(\mathrm{t}-1)$ & Inflation $(\mathrm{t}+\mathrm{n})$ & Output Gap $(\mathrm{t}+\mathrm{m})$ & Standard Error & Adjusted $R^{2}$ & Implied Neutral Cash Rate \\
\hline \multirow{2}{*}{2.52} & 0.93 & 1.09 & 3.40 & & & \\
$(0.01)$ & $(0.00)$ & $(0.0)$ & $(0.00)$ & 0.46 & 0.86 & 5.25 \\
& & $(\mathrm{n}=4)$ & $(\mathrm{m}=1)$ & $(0.43)$ & & \\
\hline
\end{tabular}

Note. The instrument list includes the cash rate (-2), the inflation rate (-2), the output gap (-1), the federal funds rate (-2), the trade-weighted index $(-1,-2)$, oil prices $(-1)$, commodity prices $(-1)$ and the unemployment rate $(-1)$. The numbers in the brackets next to the standard error are the standard errors from the backward-looking reaction function when it adds the cash rate lagged one period in the regression model. The significant level of the parameters is 5 percent.

The four parameter estimates are $\hat{\alpha}=2.52, \hat{\rho}=0.93, \hat{\beta}=1.09$, and $\hat{\gamma}=3.40$. Apart from the longer sampling period, the magnitude of the parameter estimate for $\beta$ is greater than 1 . The estimate of $\gamma$ is significantly higher. The GFC caused an increase in the output gap, and it is reasonable that the parameter of the sampling output gap is greater compared to that of de Brouwer and Gilbert (2005), in which t, a period of stable economic activity, is investigated. Since $\hat{\beta}>1$, the target real interest rate is adjusted to stabilize inflation and output (for $\hat{\gamma}>0$ ), and likewise if inflation goes up by $1 \%$, monetary authorities are predicted to raise interest rates by $1.09 \%$. The J-test statistic is 1.073352 and is asymptotically Chi-squared with 3 degrees of freedom (7 instruments minus 4 parameters). The corresponding p-value is 0.783511 . Since the p-value is very large, the validity of the instrument and overall specification of the model cannot be rejected. 
Last but not least, the standard error of the estimate is smaller than that of the full sample period. Since the sub-period fits the model better than the full sample period, inflation targeting on monetary policy serves to provide an anchor for expectations about future inflation. Policymakers would rely on the basis of this target to formulate the cash rate and stabilize the price level, avoid an insecure money supply, control the financial market, and ultimately avoid obstructing ongoing economic growth. Inflation parameters and output gap parameters are fairly close, which means that in terms of the inflation targeting period, the RBA considers the weights of these two variables equally in order to stabilize the economy.

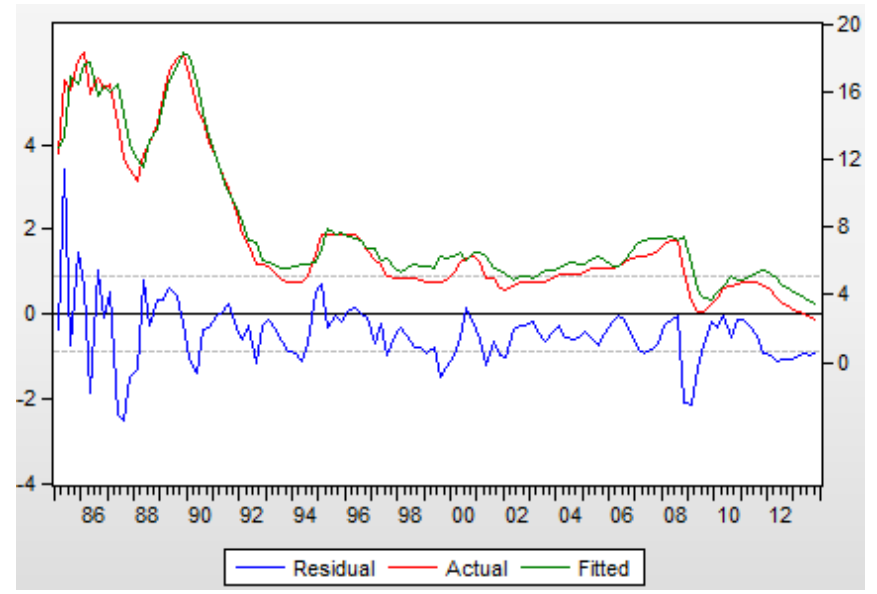

Figure 9. Predicted cash rate by the forward-looking reaction function versus the RBA cash rate

Figure 9 shows the actual, the fitted, and the residual values of the cash rate with respect to GMM-estimated results in Table 3. A striking feature is that the forward-looking reaction function generates the implied cash rate which is fairly close to the RBA's decisions. The high interest rate in the late 1980s was unexpected in response to the rational expectation one year ahead of the forecast profile. The big jump in the cash rate of late 1994 and early 1995 was also unexpected in terms of the rational expectation of the forecast profile. In the first half of the 2000s, the fitted cash rates were in line with the actual rate. At the end of 2008 and the beginning of 2009, the big drop in nominal interest rates as an impact of the GFC was not something that was predictable on the basis of rational expectations one year ahead of forecasts. These outcomes indicate that the forward-looking Taylor rule broadly matches policy rates during periods of low volatility in inflation and business cycle fluctuations. On the other hand, the forward-looking reaction function may overestimate or underestimate policy rules in the case of unpredictable shocks, but it will rapidly adjust the forecast profile for inflation and output fluctuations so as to capture the movement of the RBA cash rate. Overall, the results in Figures 8 and Figure 9 imply that the forward-looking specification does a better job of describing the actual interest rate than the backward specification.

The final goal is to calculate the implied neutral rate of interest from the forward-looking model. As mentioned in Section 6, $\alpha \equiv \bar{\imath}-\beta \pi^{*}$. Given the constant value in Table 3 and a constant target inflation rate of $2.5 \%$, the average of the target band, the implicit neutral cash rate $\bar{l}$ is calculated as $2.52+(2.5 \times 1.09)=5.25$. Note that all the estimated parameters are statistically significant at a significance level of $10 \%$.

\section{Out-of-Sample Forecasts}

Previous sections examine monetary policy under the backward-looking specification and the forward-looking specification using an in-sample fit. This section examines the backward-looking function and the forward-looking function in terms of out-of-sample fit. This study uses the HP filter to generate the potential output and output gap in two steps. First, the in-sample period is defined from quarter 2, 1984, to quarter 4, 2007. Second, for the out-of-sample prediction of the interest rate, this study uses the output gap from the previous estimation from quarter 1, 2008 to quarter 4, 2014. The first period output gap is then substituted into the model, again using OLS and GMM to compute the estimated parameters of inflation and output gap for the backward-looking function and the forward-looking function, respectively. These estimated parameters are applied in the out-of-sample period to investigate how fitted cash rates from the backward-looking specification and the forward-looking specification fit the actual cash rate from the RBA (Note 4). This section addresses how the forecast profile in the forward-looking specification assists the process of capturing the true movement of the RBA cash rate. It is then compared with the backward-looking specification where there is no forecast 
procedure.

After computing the fitted cash rate, derive the standard error (SE) of the out-of-sample model. From this figure, compare the in-sample and out-of-sample SE between and across two reaction functions. The out-of-sample standard error is calculated from the following equations:

$$
\begin{gathered}
\text { Mean Square Error (MSE) }=\frac{1}{28} \sum_{2008 Q 1}^{2014 Q 4}\left(i_{t-\hat{\imath}_{t}}\right)^{2}, \\
\mathrm{SE}=\sqrt{M S E} .
\end{gathered}
$$

The number of observations in the out-of-sample period is 28 quarters.

\section{Backward-Looking Reaction Function - Out-of-Sample Forecasts}

Table 5 shows the estimated parameters of the in-sample period, and they are all statistically significant. In addition, the in-sample model represents a much smaller standard error (SE) than the out-of-sample model. Recall that the smaller the SE, the better the fit of the estimated model to the cash rate data. Figure 10 shows the out-of-sample fit of the backward-looking specification using in-sample estimated parameters. It depicts the fact that past information cannot provide observations about an unpredictable shock of the future. From the beginning of the GFC, the fitted cash rates are always overestimated in the RBA's decisions. Hence, historical data are inconsistent with the expected movement of inflation and output.

Table 5. Out-of-sample backward-looking reaction functions (1984Q2 - 2007Q4)

\begin{tabular}{cccccc}
\hline Constant & Inflation Gap (t-1) & Output Gap (t-1) & Standard Error (in-sample) & Standard Error (out-of-sample) & Adjusted $R^{2}$ \\
\hline 5.86 & 1.09 & 0.56 & 1.81 & 2.43 & 0.83 \\
$(0.00)$ & $(0.00)$ & $(0.00)$ & & & \\
\hline
\end{tabular}

Note. Empirical results from in-sample model and standard errors calculated from the out-of-sample model.

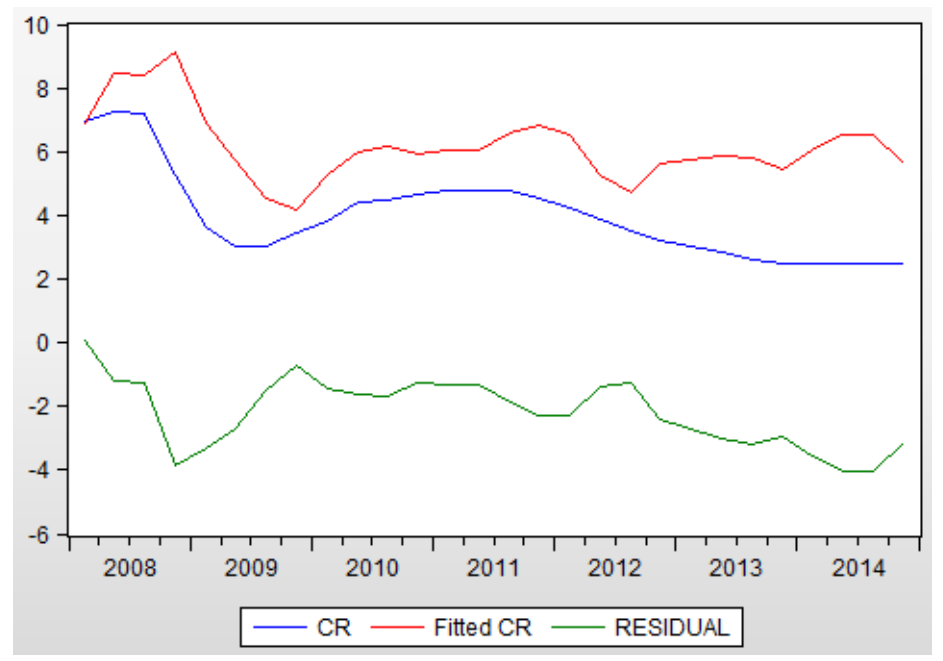

Figure 10. Fitted cash rate computed by out-of-sample backward looking reaction function

\section{Forward-Looking Reaction Function - Out-of-Sample Forecasts}

Table 6 represents the findings of the in-sample model and the estimation of the out-of-sample model. Except for the constant parameters, the rest of the results are statistically significant. Unlike the out-of-sample fit from the backward-looking specification, the forward-looking function shows that the out-of-sample model fits the cash rate data better than the in-sample model, as it generates a smaller standard error, which is the standard deviation from the estimated model. Tables 5 and Table 6 show a comparison of the backward-looking standard errors and the forward-looking out-of-sample standard errors, where it can be concluded that the backward-looking reaction function falls short of the forward-looking rule. This, in turn, means that monetary authorities explicitly consider the importance of the forecast profile, treating it as the major component of policy input when they decide the changes in nominal interest rate. Figure 11 shows the forward-looking out-of-sample fitted cash rate versus the real interest rate. Nevertheless, sometimes, the forward-looking rule still overestimates or underestimates the cash rate due to the consequences of unobservable shocks, but overall, it still provides an outlook of how the RBA sets up monetary policy on the basis of economic rational expectation. 
Table 6. Out-of-sample forward-looking reaction functions (1984Q2 - 2007Q4)

\begin{tabular}{ccccccc}
\hline Constant & $\begin{array}{c}\text { Cash Rate } \\
(\mathrm{t}-1)\end{array}$ & Inflation $(\mathrm{t}+\mathrm{n})$ & $\begin{array}{c}\text { Output Gap } \\
(\mathrm{t}+\mathrm{m})\end{array}$ & $\begin{array}{c}\text { Standard Error } \\
\text { (in-sample) }\end{array}$ & $\begin{array}{c}\text { Standard Error } \\
\text { (out-of-sample) }\end{array}$ & Adjusted $R^{2}$ \\
\hline 0.17 & $0.87(0.00)$ & $\begin{array}{c}2.24(0.00) \\
(\mathrm{n}=4)\end{array}$ & $\begin{array}{c}2.57(0.00) \\
(\mathrm{m}=1)\end{array}$ & 0.83 & 0.63 & 0.96 \\
\hline 0.66$)$ & & & & 0.63 & \\
\hline
\end{tabular}

Note. Empirical results from in-sample model and standard error calculated from out-of-sample model.

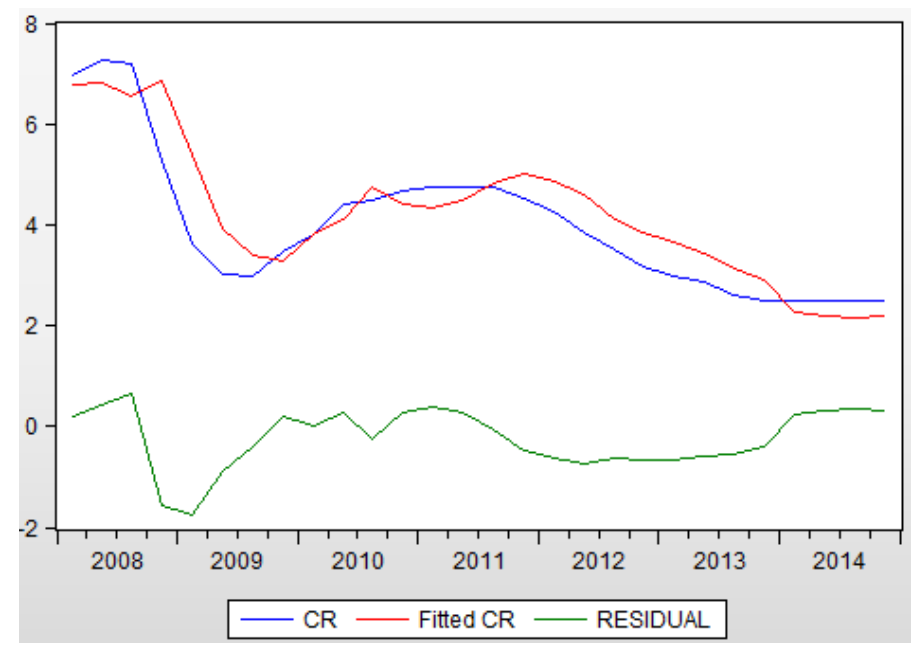

Figure 11. Fitted cash rate computed by out-of-sample forward-looking reaction function

\section{Conclusion}

Estimation of the monetary policy reaction function can enhance appreciation of the specific components ultimately affecting central bank decisions. There is a great deal of research on the monetary policy of OECD countries, while only limited empirical research exists on Australian monetary policy. Previous research finds that differences exist among countries on the question of whether the monetary authority's actions only focus on expected inflation or also concern expected output growth. This study addresses the question of how the RBA implements its monetary policy to maintain price stability and conserve domestic economic wellbeing. In this study, two specifications of the Taylor rule are considered and fit Australian economic conditions. This study looks at the estimations of the backward-looking response function based on Taylor (1999) and the forward-looking response function from Clarida et al. (1998) and de Brouwer (2005). This study extends the original Taylor rule into economic components utilized in different response functions of the Taylor rule to analyze the monetary policy and the RBA's implementation in the post-floated cash rate period and the inflation targeting period.

Overall, upon addressing both models, one can conclude that empirical evidence plainly shows that the forward-looking reaction function outperforms the backward-looking reaction function. The backward-looking reaction function provides a brief interpretation of how the RBA implements the short-term nominal interest rate in response to changes in inflation and output. However, due to its simplicity, it ignores the future expectation of policy variables and also many other valid instruments that can affect inflation variability and output fluctuation. The forward-looking approach, which combines lagged values of variables one year ahead of forecasting, is more likely to capture the appropriate movement of the cash rate. Meanwhile, Kahn, Koenig, and Leeson (2012) advocate for the forward-looking approach since it is a true real-time policy that formulates the reaction function with respect to available forecasted information at the time that monetary decisions are made. The forward-looking approach is explicitly preferred as it considers the role of forecasting macroeconomic movements in finalizing decisions.

Both the exchange rate of Australian dollar in terms of U.S. dollar, as well as the Fed Funds Rate, is included in the forward-looking specification since the RBA is sensitive to the adjustment of U.S. Federal Reserve. However, this does not mean that the Australian cash rate is dependent on the movement of U.S. interest rates. The Federal Reserve's actions provide a general vision of the world's largest economy; changes in the Federal Funds Rate, would therefore affect the global economy and the global financial market as well as the economic input of the RBA at the time that they formulate their monetary policies. 
Future research will focus on the forward-looking reaction function and also consider the lagged values of inflation and output with the rational expectation of these two variables, therein achieving a direct investigation of the forward-looking specification versus the backward-looking specification. Subsequent research may further include more instruments which are significantly related to inflation, output and the nominal cash rate. These additional instruments may generate a more detailed estimation of the reaction function and provide a comprehensive outlook for monetary policy in Australia.

\section{References}

Batini, N., \& Haldane, A. (1999). Monetary Policy Rules and Inflation Forecasts. Bank of England Quarterly Bulletin, February, 60-67.

Bernanke, B. (2007). Opening Remarks. Remarks at the Conference on John Taylor's Contributions to Monetary Theory and Policy.

Bernanke, B. (2010). Monetary Policy and the Housing Bubble. Speech at the Annual Meeting of the American Economic Association, Atlanta, Georgia.

Bryant, R., Hooper, P., \& Mann, C. (Eds.) (1993). Evaluating Policy Regimes: New Empirical Research in Empirical Macroeconomics. Brookings Institution, Washington, D. C.

Clarida, R., Gali, J., \& Gertler, M. (1998). Monetary Policy Rules in Practice: Some International Evidence. European Economic Review, 42, 1033-67. https://doi.org/10.1016/S0014-2921(98)00016-6

Clarida, R., Gali, J., \& Gertler, M. (2000). Monetary Policy Rules and Macroeconomic Stability: Evidence and Some Theory. Quarterly Journal of Economics, 65, 147-180. https://doi.org/10.1162/003355300554692

De Brouwer, G., \& Gilbert, J. (2005). Monetary Policy Reaction Functions in Australia. The Economic Record, 81(253), 124-134. https://doi.org/10.1111/j.1475-4932.2005.00238.x

De Brouwer, G., \& O'Regan, J. (1997). Evaluating Simple Monetary Policy Rules for Australia. In P. Lowe (Ed.), Monetary Policy and Inflation Targeting (pp. 244-276). Reserve Bank of Australia, Sydney.

Edey, M. (2006). An Australian Perspective on Inflation Targeting, Communication, and Transparency. Monetary Policy in Asia: Approaches and Implementation, 31, 3-24.

Friedman, M. (1960). A Program for Monetary Stability. New York: Fordham University Press.

Gruen, D., Robinson, T., \& Stone, A. (2005). Output Gaps in Real Time: How Reliable Are They? Economic Record, 81, 6-18. https://doi.org/10.1111/j.1475-4932.2005.00212.x

Hansen, L. P. (1982). Large Sample Properties of Generalized Method of Moments Estimators. Econometrica, 50, 1029-1054. https://doi.org/10.2307/1912775

Hofmann, B., \& Bogdanova, B. (2012). Taylor Rules and Monetary Policy: A Global 'Great Deviation? BIS Quarterly Review.

Kahn, G., Koenig, E., \& Leeson, R. (2012). The Taylor Rule and the Transformation of Monetary Policy. Standard, California: Hoover Institution Press.

Lee, K., Morley, J., \& Shields, K. (2011). The Meta Taylor Rule. Discussion Papers 11/07, University of Nottingham, Centre for Finance, Credit and Macroeconomics (CFCM).

Lee, K., Olekalns, N., \& Shields, K. (2012). Meta Taylor Rules for the UK and Australia; Accommodating Regime Uncertainty in Monetary Policy Analysis using Model Averaging Methods. Working Papers Series 1138, The University of Melbourne.

Orphanides, A. (1998). Monetary Policy Rules Based on Real-Time Data. Finance and Economics Discussion Paper No. 98-03, Board of Governors of the Federal Reserve System.

Orphanides, A. (2007). Taylor Rules. Finance and Economics Discussion Series, Divisions of Research \& Statistics and Monetary Affairs, Federal Reserve Board, Washington, D.C. https://doi.org/10.2139/ssrn.999563

Orphanides, A., \& Van Norden, S. (2001). The Unreliability of Output Gap Estimates in Real Time. Centre for Inter-University Research and Analysis on Organizations Working Paper No. 2001s-57.

Orphanides, A., \& Van Norden, S. (2004). The Reliability of Inflation Forecasts Based on Output Gap Estimates in Real Time. Finance and Economics Discussion Series, Divisions of Research \& Statistics and Monetary Affairs, Federal Reserve Board, Washington, D.C. 
Taylor, J. B. (1993). Discretion versus Policy Rules in Practice. Carnegie-Rochester Conference Series on Public Policy, 39, 195-214. https://doi.org/10.1016/0167-2231(93)90009-L

Taylor, J. B. (1999a). A Historical Analysis of Monetary Policy Rules. In J. Taylor (Ed.), Monetary Policy Rules (pp. 319-348). NBER, Chicago. https://doi.org/10.7208/chicago/9780226791265.001.0001

Taylor, J. B. (1999b). Introduction. In J. Taylor (Ed.), Monetary Policy Rules (pp. 1-14). NBER, Chicago. https://doi.org/10.7208/chicago/9780226791265.001.0001

Yellen, J. (2007). Policymaker Roundtable. Remarks at the Conference on John Taylor's Contributions to Monetary Theory and Policy.

\section{Copyrights}

Copyright for this article is retained by the author(s), with first publication rights granted to the journal.

This is an open-access article distributed under the terms and conditions of the Creative Commons Attribution license (http://creativecommons.org/licenses/by/4.0/). 